Article

\title{
The High Density Polyethylene Composite with Recycled Radiation Cross-Linked Filler of rHDPEx
}

\author{
David Manas ${ }^{1,+}{ }^{+}$, Miroslav Manas ${ }^{1}$, Ales Mizera ${ }^{1, *} \mathbb{0}$, Pavel Stoklasek ${ }^{1}$, Jan Navratil ${ }^{2}$, \\ Stanislav Sehnalek ${ }^{1}$ (D) and Pavel Drabek ${ }^{1}$ \\ 1 Faculty of Applied Informatics, Tomas Bata University in Zlin, CEBIA-Tech, Nad Stranemi 4511, 76005 Zlin, \\ Czech Republic; manas@utb.cz (D.M.); manas@fai.utb.cz (M.M.); pstoklasek@utb.cz (P.S.); \\ sehnalek@fai.utb.cz (S.S.); pdrabek@utb.cz (P.D.) \\ 2 SKODA AUTO a.s., tr. Vaclava Klementa 869, Mlada Boleslav II, 29301 Mlada Boleslav, Czech Republic; \\ jan.navratil@skoda-auto.cz \\ * Correspondence: mizera@utb.cz; Tel.: +420-576-035-636 \\ + This article is dedicated, in memoriam, David Manas.
}

Received: 25 October 2018; Accepted: 5 December 2018; Published: 8 December 2018

\begin{abstract}
This article discusses the possibilities of using radiation cross-linked high density polyethylene (HDPEx) acting as a filler in the original high density polyethylene (HDPE) matrix. The newly created composite is one of the possible answers to questions relating to the processing of radiation cross-linked thermoplastics. Radiation cross-linked networking is-nowadays, a commonly used technology that can significantly modify the properties of many types of thermoplastics. This paper describes the influence of the concentration of filler, in the form of grit or powder obtained by the grinding/milling of products/industrial waste from radiation cross-linked high density polyethylene (rHDPEx) on the mechanical and processing properties and the composite structure. It was determined that, by varying the concentration of the filler, it is possible to influence the mechanical behaviour of the composite. The mechanical properties of the new composite-measured at room temperature, are generally comparable or better than the same properties of the original thermoplastic. This creates very good assumptions for the effective and economically acceptable, processing of high density polyethylene (rHDPEx) waste. Its processability however, is limited; it can be processed by injection moulding up to $60 \mathrm{wt} \%$.
\end{abstract}

Keywords: High Density Polyethylene; radiation cross-linking; mechanical properties; structure; processability

\section{Introduction}

Plastic processing shows an increasing trend on an annual basis. Polymers-especially thermoplastics, are used in all industrial fields, and in a wide variety of applications-including packaging materials, household products, sports and leisure activities, medical products, and the automotive, aviation, and electro-technical and electronics fields. Concurrent with the production processes, large quantities of waste are generated and products at the end of their life-cycle accumulate. The quality of waste polymers depends on their origin, way of collection, and contamination by other types of polymers, or organic or inorganic pollution [1,2].

At present, more than one third of this waste is recycled, the same amount is landfilled, or used for energy recovery purposes [3]. Waste treatment methods vary considerably and involve several simple or complex operations like collecting, sorting cleaning and grinding them. Ground waste of a known source and composition can be used directly as additives to the original material or be processed into a granular form. The waste collection methods differ from country to country. Eventual 
contamination of this waste or plastic mixes of an unknown type can lead to problems in the course of their further processing [3-15]. Apart from material recycling, different chemical recycling methods are also used [4]. Recently, the issue of processing polymeric materials into synthetic gases has been addressed very intensively [16-19].

Along with the enormous developments in the processing of polymers field, so too has grown the significance of processing polymer waste. The latest data shows that the capacity for processing polymer waste is growing world-wide. In Europe, $31 \%$ of all extrusion capacity is recycled. Capacity is growing, especially in the processing of flexible plastic waste from households. Furthermore, there is a problem with the processing of multi-layer materials, which continue to remain un-recyclable [20,21]. Even the USA is seeing ever greater attention being paid to the processing of polymer wastes. The volume of rigid plastics collected for recycling in 2016 was nearly 4.5 times greater than that collected in 2017; while plastic of film recycling has grown for 12 consecutive years and more than doubled in comparison with 2005 [22]. Research has also been conducted into the prediction of the life-cycle of polymer films from polyolefins and biodegradable plastics [23,24].

Technologies that re-melt polymer waste are suitable for thermoplastics. This processing method; however, is not applicable to cross-linked thermoplastics, especially due to the impossibility of re-melting them. Modification of thermoplastics by cross-linking, in particular by radiation networking, is on the industrial scale, becoming increasingly widespread. The cross-linking process allows one to modify the properties of thermoplastics, in particular to improve their mechanical properties, to increase their temperature and chemical resistance, and thereby, to significantly increase the application potential of these materials. Some thermoplastics, like polyethylene (PE) for instance, cross-link without the addition of cross-linking agents. Others, for instance, polypropylene (PP) or polyamides (PA), require cross-linking agents in order to cross-link [25-27].

In line with the increasing share of such modified thermoplastics, so too does the share of waste generated by its own cross-linking and, in particular, the products of cross-linked thermoplastics at the end of their lifetime. Radiation cross-linking allows significant improvements in some properties, but the possibility of recycling in traditional ways is ruled out. Radiated cross-linked polymers lose their ability due to the creation of spatial networks in the original thermoplastics to be re-meltable [28-34]. Therefore, the processing/recycling of radiation cross-linked thermoplastics is much more complicated when compared to the original polymer; so far, there are no effective ways to recycle these materials on an industrial scale. Research on radiation-cross-linked HDPEx on the properties of HDPEx-LDPE composites has shown that the composite formed in this way is processable by conventional techniques used in the processing of thermoplastics, in particular by injection moulding technology. A higher content of HDPEx filler in the LDPE matrix makes composite processability worse. Most of the mechanical properties of the composite are significantly better than the mechanical properties of the matrix itself [32-34]. The use of recycled cross-linked rHDPEx as a filler in low density polyethylene (LDPE) is described in the work [35].

This paper presents a study of the possibility of cross-linked high density polyethylene (rHDPEx) waste recycling as a filler in original (virgin) HDPE. There is described the possibility of creating a new type of high density polyethylene (HDPE) composite with a high density polyethylene radiation cross-linked filler (rHDPEx) and the influence of content of HDPEx filler on its characteristics and structure.

\section{Materials and Methods}

\subsection{Material}

The wide availability of rHDPEx was the main reason for the use of this polymer in the research presented herein. This material was supplied in the form of heating pipes used for underfloor heating systems. The pipes were crushed using a MASKIN AB RAPIS S-33010, low-speed knife mill, screen-size $5 \mathrm{~mm}$ and ground using a Condux toothed disc mill. To obtain crushed or powdered material for 
further processing, the particles with dimension higher than $1 \mathrm{~mm}$ were separated from the powder using a $1 \mathrm{~mm}$ screen. High density polyethylene (HDPE-Tipelin 6300B, Slovnaft, Bratislava, Slovakia) was chosen as the polymer matrix regarding its ease of processability, low price and wide availability. HDPE granulate was used as the polymer matrix and rHDPEx in grit or powder states were used as the filler.

\subsection{Irradiation}

The irradiation of used HDPE pipes originally intended for use in underfloor heating systems was originally carried out at the BGS Beta-Gamma-Service company, Germany premises. Electron beam radiation, at the dose of $165 \mathrm{kGy}$, and energy of $10 \mathrm{MeV}$ was used for their irradiation. The cross-linking of used HDPE was realised without the use of a cross-linking agent. Gel content measurement and a dosimeter were used to determine and find proof of correctness. The correct radiation dose was checked by a nylon FTN 60-00 dosimeter; and the analysis was performed using a Genessis 5 spectrophotometer in correspondence with the ASTM 51261 standard [36]. Gel content was measured according to the ASTM D7567 standard [37], which is determined by means of its solvent extraction with xylene. The dose of $165 \mathrm{kGy}$ corresponds to $60 \%$ gel content.

\subsection{Specimen Preparation}

From crushed and powdered material, two types of mixtures which differ from each other by filler state (grit or powder rHDPEx) were prepared: mixture A (HDPE granulate + rHDPEx grit) and mixture B (HDPE granulate + rHDPEx powder). Crushed (particle sizes of 1-5 mm) or powdered rHDPEx was mixed together with virgin HDPE granulate in a laboratory fluid mixer. A size analysis was performed using Retsch AS 200 Basic equipment for the determination of particle size distribution (Figure 1). Dimensions of $68 \%$ particles are in interval 0.5 to $1.0 \mathrm{~mm}$ and only less than $0.05 \%$ of the particles are smaller than $0.09 \mathrm{~mm}$. From this mixture, in concentrations ranging from 10 to $60 \mathrm{wt} \%$ of rHDPEx in virgin HDPE, Type 1A specimens for all tests according to the ISO 527 standard [38] were prepared by injection moulding using an Arburg Allrounder $470 \mathrm{H}$ injection moulding machine. The dimensions of specimens are given in Figure 2a and the processing conditions are given in Table 1.

15 specimens were prepared for each testing method and statistical evaluation was realised in the TestXpert II, MS Excel 2016 and MiniTab 16 programs. Arithmetic mean and standard deviation are used in all figures.

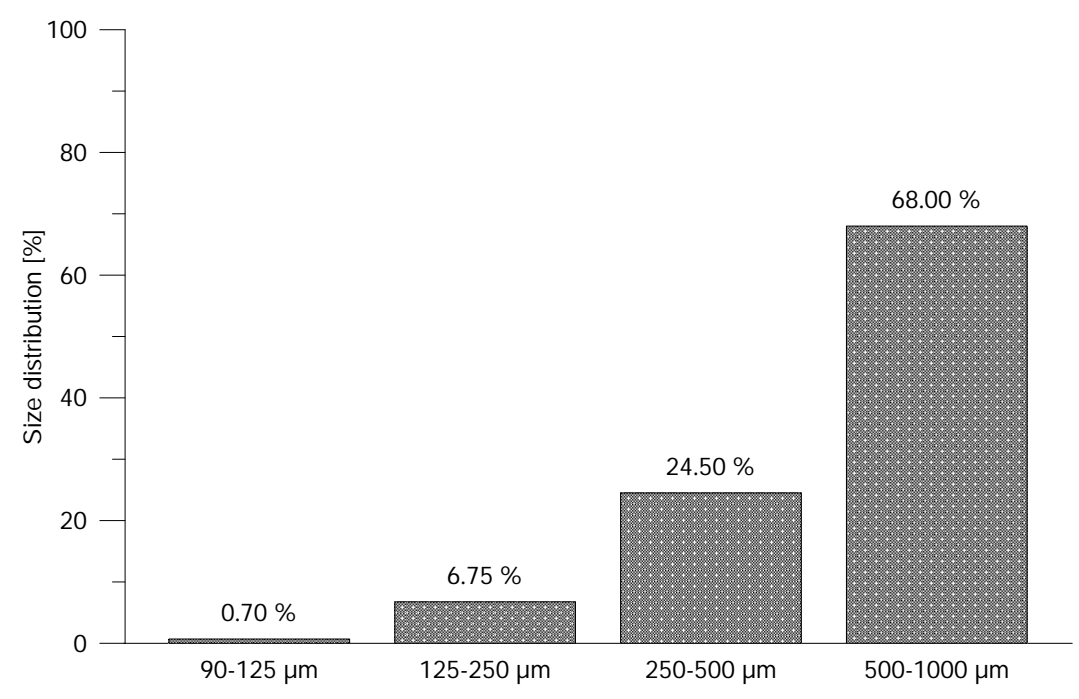

Figure 1. Powder-size distribution. 


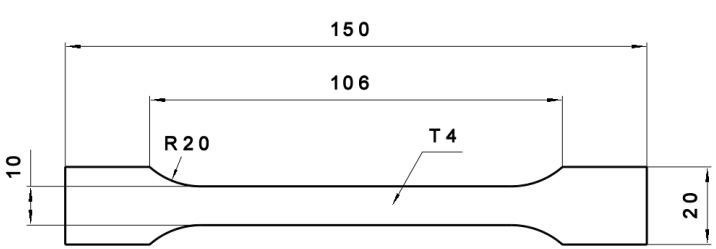

(a) Dimensions of testing specimen type 1A.

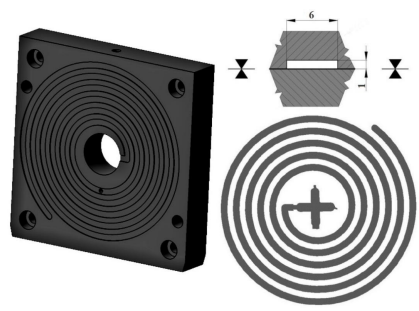

(b) Spiral cavity mould.

Figure 2. Test speciment.

Table 1. Injection moulding processing parameters.

\begin{tabular}{lcc}
\hline \multicolumn{3}{c}{ ARBURG ALLROUNDER $470 \mathrm{H}$} \\
\hline Injection Velocity & 60 & $\mathrm{~mm} \mathrm{~s}^{-1}$ \\
Injection Pressure & $80\left(100^{1}\right)$ & $\mathrm{MPa}$ \\
Cooling Time & 20 & $\mathrm{~S}$ \\
Mould Temperature & 40 & ${ }^{\circ} \mathrm{C}$ \\
Holding Time & 25 & $\mathrm{~S}$ \\
Holding Pressure & $60\left(85^{1}\right)$ & $\mathrm{MPa}$ \\
\hline \multicolumn{4}{c}{ Temperature of Plasticizing Unit Zones } \\
\hline Temperature under the Hopper & 60 & ${ }^{\circ} \mathrm{C}$ \\
Temperature Zone 1 & 200 & ${ }^{\circ} \mathrm{C}$ \\
Temperature Zone 2 & 215 & ${ }^{\circ} \mathrm{C}$ \\
Temperature Zone 3 & 220 & ${ }^{\circ} \mathrm{C}$ \\
Temperature Zone 4 & 235 & ${ }^{\circ} \mathrm{C}$ \\
Temperature Zone 5 & 250 & ${ }^{\circ} \mathrm{C}$ \\
\hline \multicolumn{1}{c}{ used at the highest concentration of filler $(60 \mathrm{wt} \%)}$.
\end{tabular}

\subsection{Polymer Mixture Fluidity}

A modified spiral test was performed using a spiral cavity mould [39] with a spiral length of $2000 \mathrm{~mm}$; the shape of the cavity is rectangular, its dimensions were $6 \mathrm{~mm} \times 1 \mathrm{~mm}$ (Figure $2 \mathrm{~b}$ ). An Arburg Allrounder $470 \mathrm{H}$ injection moulding machine was used for the preparation of test spirals. The injection moulding processing conditions are the same as in the "Specimen preparation" paragraph (Table 1).

\subsection{Tensile Test}

A ZWICK 1456 tensile machine was used for the estimation of tensile behaviour. Measurements were carried out according to the ISO 527 standard [38] - at ambient $\left(23^{\circ} \mathrm{C}\right)$ and elevated $\left(80^{\circ} \mathrm{C}\right)$ temperatures; crosshead speed: $50 \mathrm{~mm} / \mathrm{min}$. The E-modulus and ultimate tensile strength were all evaluated from these measurements. Conditioning was taken for 5 days in temperature of $23{ }^{\circ} \mathrm{C}$ and relative humidity of $50 \%$.

\subsection{Shore D Hardness (ShD)}

An OMAG AFRI ART 13 Shore D hardness tester was used for hardness testing in accordance with the ISO 868 standard [40], therefore holding time was $15 \mathrm{~s}$.

\subsection{Vicat Softening Temperature}

An HDT 6 Vicat CEAST type 6921 device was used to measure the Vicat softening temperature (VST). The test was carried out in accordance with the CSN EN ISO 306/A50 standard [41]. The test specimens were heated in an oil bath, at a heating rate of $50{ }^{\circ} \mathrm{C} / \mathrm{h}$. The VST was automatically detected at a penetration point of $1 \mathrm{~mm}^{2}$ to $1 \mathrm{~mm}$ depth of the test body; the loading force was $10 \mathrm{~N}$. 


\subsection{Structural Analysis}

A LEICA RM2255 microtome was used for the preparation of samples, (thickness of $35 \mu \mathrm{m}$ ) and an OLYMPUS BX41 microscope was used for the structural analysis. Equally, the structure was investigated on the fracture area with nitrogen-cooled bodies using a JEOL 7500F scanning electron microscope.

\section{Results and Discussion}

Two types of mixtures A (HDPE + rHDPEx grit) and B (HDPE + rHDPEx powder) were prepared and tested. The basic processing characteristics of the polymer blend with different doses of filler (rHDPEx) were measured and changes in the mechanical properties of the studied HDPE + rHDPEx composite were monitored.

The basic processing properties of the polymers and their possible mixtures are usually characterised by the melt flow index (MFI). Due to the rHDPEx particle size and the impossibility of re-melting, MFI measurements could not be performed. A flow modified spiral test was performed to assess flow properties because of possibility of using a high injection rate and filling pressure which caused that melted HDPE and softened rHDPEx pass through injection gate with dimensions $6 \times 1 \mathrm{~mm}$. From the measured data, it is clear that the filler content (rHDPEx) significantly influences the polymer melt viscosity. The length of the spiral arrest decreased as the filler content increased. The flow properties of the A and B mixtures deteriorated at the filler content of $10 \mathrm{wt} \%$, where the spiral length was $8 \%$ lower and decreased steadily with a further increase in the proportion of the filler. At the maximum dose rHDPEx of $60 \mathrm{wt} \%$ in the original HDPE led to a drop in the spiral length by up to $37 \%$ as compared to HDPE. This filler content ( $60 \mathrm{wt} \%$ ), appears to be the boundary limit, since, with a higher rHDPEx content it was no longer possible to process the mixture. A similar trend can be observed for mixture B (HDPE + rHDPEx powder) with very small differences between the measured values of both mixtures (Figure 3).

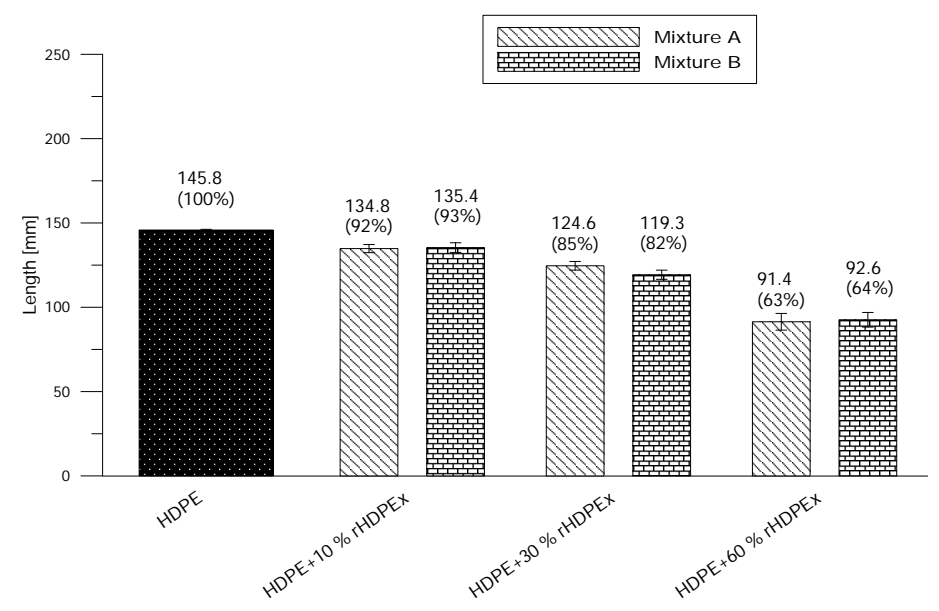

Figure 3. Polymer fluidity comparison-mixtures A, B.

The measurements made show that mechanical properties are also influenced by the filler content. Dose $10 \mathrm{wt} \%$ rHDPEx causes the E-modulus (modulus of elasticity) to increase by up to $12 \%$ (mixture A) and $9 \%$ (mixture B) in both tested mixtures. The greatest decrease in the E-modulus was recorded at the highest concentration of filler (HDPEx) in the form of a powder. Since a slight decrease in the E-modulus occurred at the same concentration in the A mixture, these changes can be attributed in particular to worsening of the processability/miscibility of the mixture at the highest concentrations of the filler. As the filler concentration increases, the E-modulus gradually decreases slightly. With regard to the measurement error, it can be stated that the E-modulus of both test mixtures, measured at room temperature $\left(23^{\circ} \mathrm{C}\right)$ at a filler concentration of 30 and $60 \mathrm{wt} \%$ is approximately the 
same as the E-modulus of the matrix itself (virgin HDPE), which is very important from the usability in working practise perspective (Figure $4 \mathrm{a}$ ). The E-modulus of mixture A at elevated temperature $\left(80{ }^{\circ} \mathrm{C}\right)$ shows significant changes with a maximum increase of $25 \%$ at a filler content of $10 \mathrm{wt} \%$. Mixture B results in a gradual increase in the value of the E-modulus and at the maximum filler content-(60 wt \%). The E-modulus at $60 \mathrm{wt} \%$ is approximately the same as that of A (Figure $4 \mathrm{~b}$ ). In both cases, the E-modulus values measured in the course of increasing the temperature are higher across the full range of filler doses are higher by 9 to $25 \%$ than the matrix (HDPE).

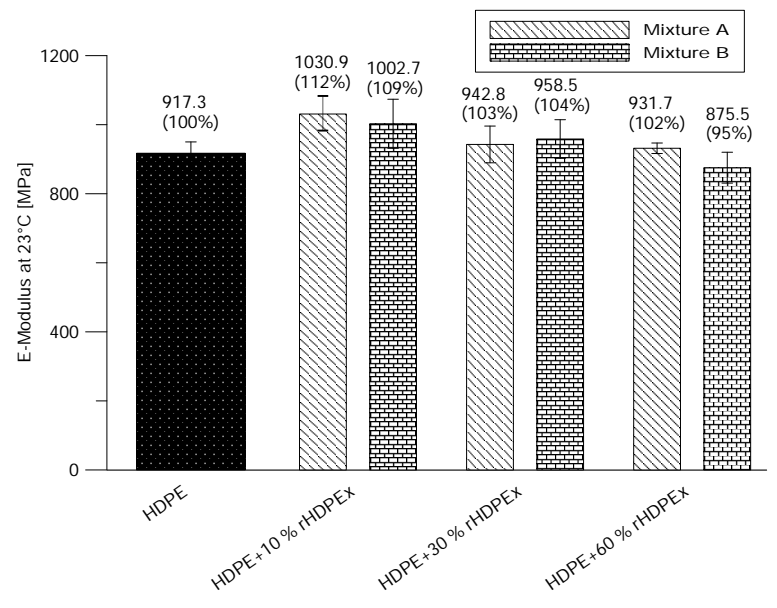

(a) At ambient temperature

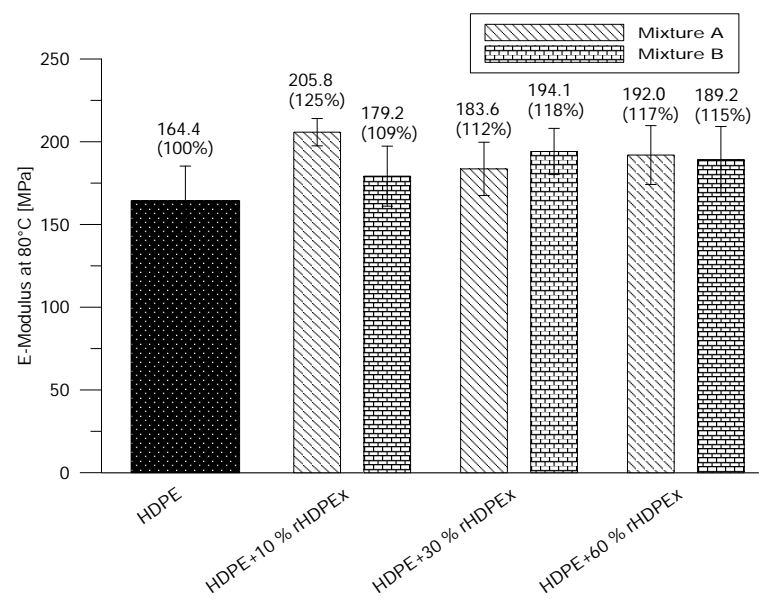

(b) At elevated temperature

Figure 4. E-modulus of mixtures A, B.

For both mixtures, the strength (measured at $23^{\circ} \mathrm{C}$ ) increased slightly, in line with the increasing charge of the filler with a maximum increase of $8 \%$ for mixture A and a dose of $10 \mathrm{wt} \%$ filler; or respectively, $9 \%$ for mixture $\mathrm{B}$, at a dose of $30 \mathrm{wt} \%$ filler. At the maximum filler content $(60 \mathrm{wt} \%)$, tensile strength is slightly higher than the tensile strength of the matrix (HDPE) itself (Figure 5a). The tensile strength of the two test mixtures, measured at an elevated temperature $\left(80^{\circ} \mathrm{C}\right)$ is more pronounced. Along with the increasing filler dose, the strength limit gradually increases with the maximum of $11 \%$ for mixture A; and respectively, of $14 \%$ for B, at the maximum filler content ( $60 \mathrm{wt} \%$ ). The tensile strength at elevated temperature is higher than the tensile strength of the matrix (Figure $5 \mathrm{~b}$ ).

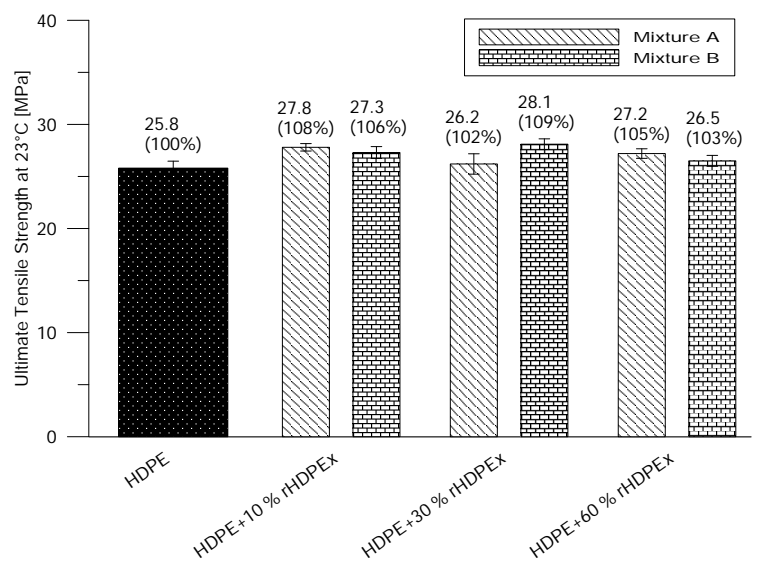

(a) At ambient temperature

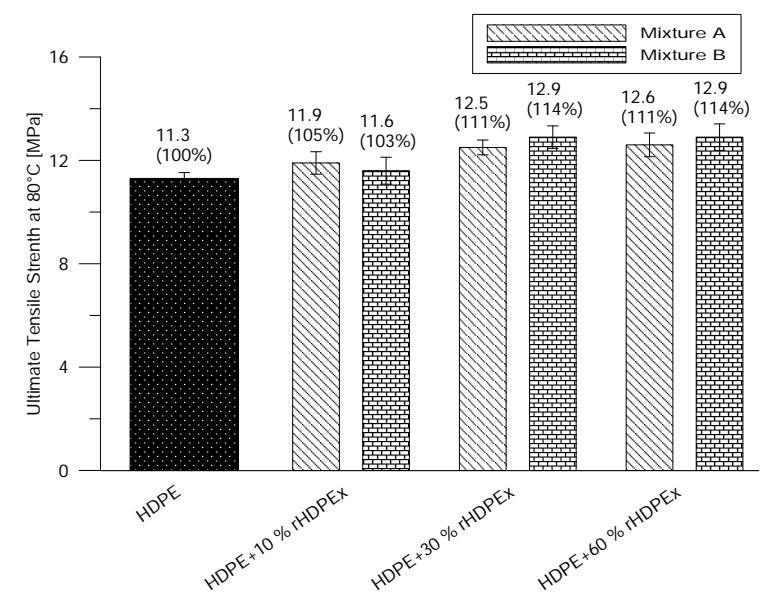

(b) At elevated temperature

Figure 5. Ultimate tensile strength of mixtures A, B. 
The Shore D hardness of both of the tested mixtures with the filler dose declined slowly. The minimum hardness (9\% lower than the matrix hardness) was measured for a mixture with a filler dose of $60 \mathrm{wt} \%$ (Figure 6).

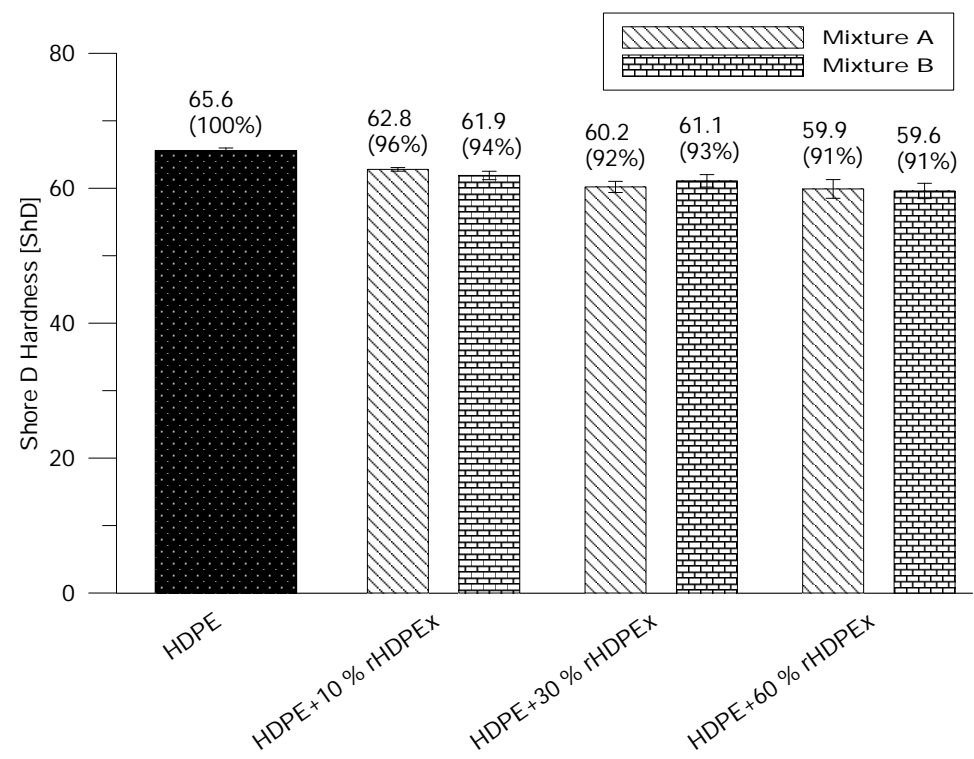

Figure 6. Shore D hardness-mixtures A, B.

In the course of measuring the VST, no changes were recorded for both mixtures when comparing HDPE to HDPEx (Figure 7).

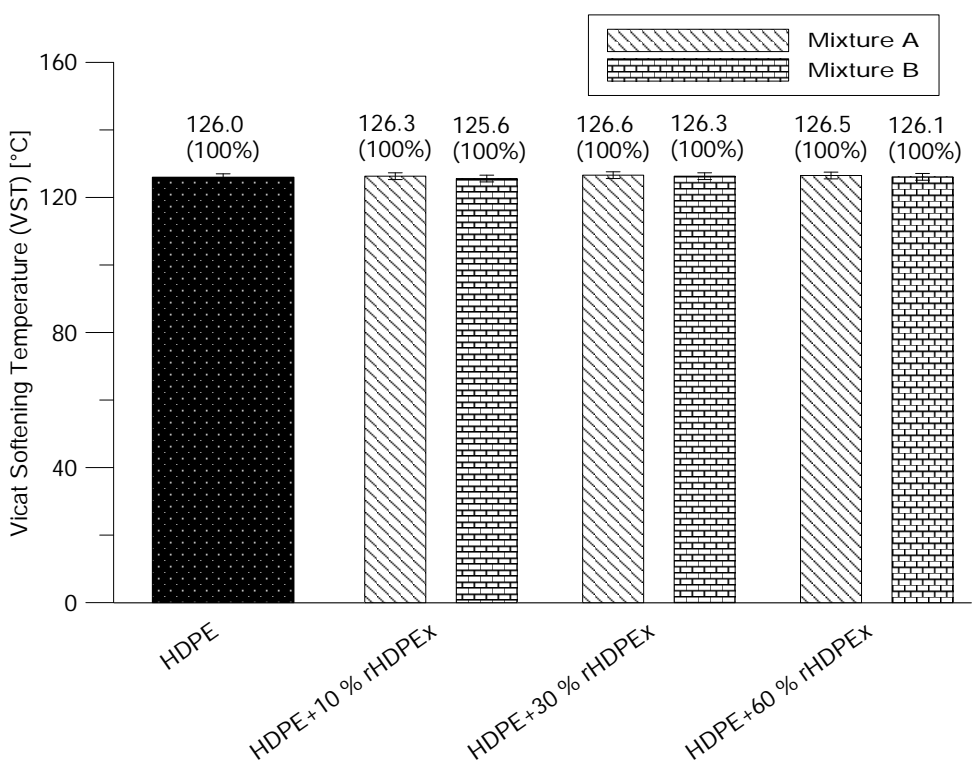

Figure 7. Vicat testing-mixture A, B.

Figure 8 shows the microtome cuts of mixture A. At all concentrations, the perfect fit of the rHDPEx filler material can be observed, which is coated with HDPE without visible damage even at a concentration of $60 \mathrm{wt} \%$ rHDPEx filler. Similar features can be seen in Figure 9, where rHDPEx powder was added instead of grit at the same filler concentration. Figure 9, shows better dispersion as compared to the grit. Structural tests confirmed these findings. However, the mechanical properties show that the additional grinding process is economically disadvantageous when the properties remain similar to those of the less-costly crushing process. 


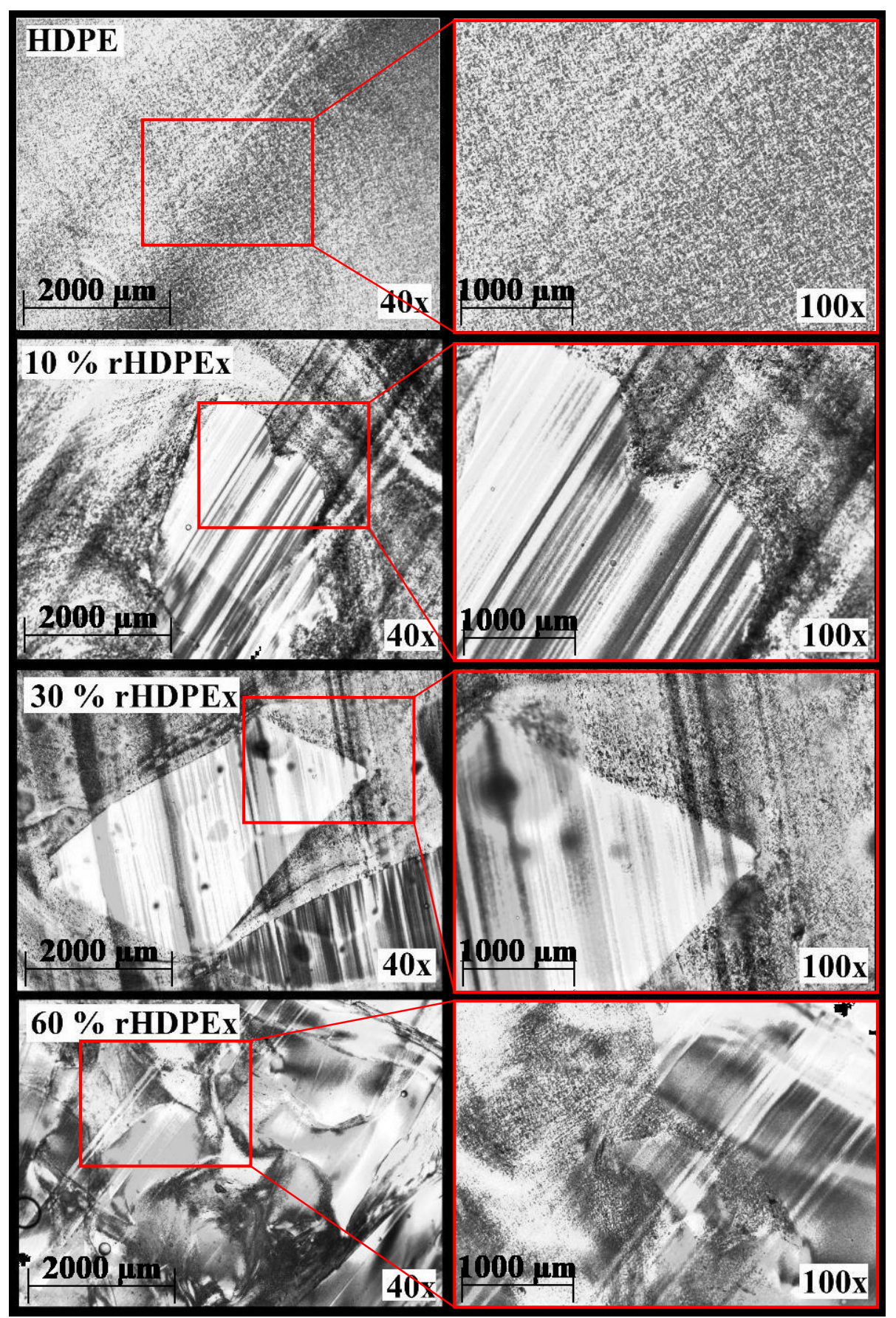

Figure 8. Microtome cuts of mixture A.

Lastly, the SEM of the fracture surface-(low-temperature-liquid $\mathrm{N}_{2}$ ) was used-as shown in Figure 10. The orientation of the lamellae can be observed on the HDPE fracture surface. In contrast, HDPEx has a cross-linked structure, which occurs on the fracture surface by the tearing of bonds. When HDPEx is crushed or ground, there is a splitting of particles with a rough surface that have a larger contact surface than crushed or milled HDPE. Because HDPEx is no longer meltable, it only softens-due to the large interface, and an HDPE matrix with the rHDPEx filler grit or powder is perfectly bonded. Although the mechanical properties of Mixtures A and B are similar, the fracture surface appears different. For Mixture A, the region of the tearing of the cross-linked fillers, this can be seen in Figure 10. On the other hand, Mixture B produced a perfect mix of rHDPEx powder with the HDPE matrix. The non-meltable rHDPEx powder prevented the formation of a lamellar structure 
and resulted in a cellular structure, which had similar mechanical properties to the rHDPEx grit filler. This confirms that when processing both composites, the HDPE matrix with rHDPEx filler was bonded on the interphase interface. It is likely that the melted HDPE matrix bonds with the partially melted surface of the cross-linked rHDPEx filler, (gel content 60\%). The structure of both mixtures confirms the very good and strong adhesion between the HDPE matrix and the filler-(rHDPEx). This visible interface between the matrix and the filler demonstrates that rHDPEx acts as a filler in both mixtures-A and B. From the results, it can be seen that recycled high-density polyethylene can be processed as a filler in virgin HDPE. The principle used is very simple and allows easy processing of the cross-linked polymer waste.

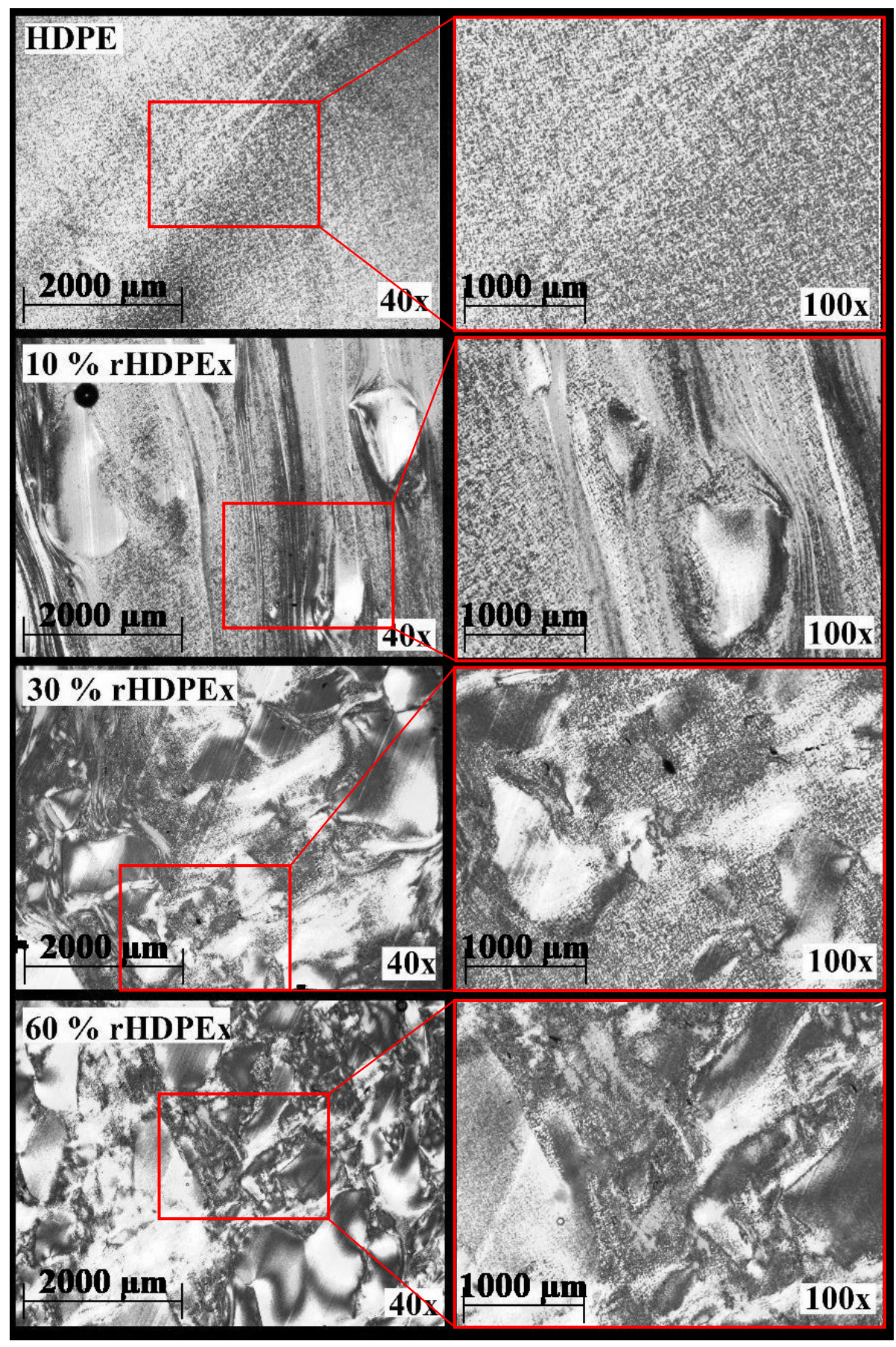

Figure 9. Microtome cuts of mixture B. 


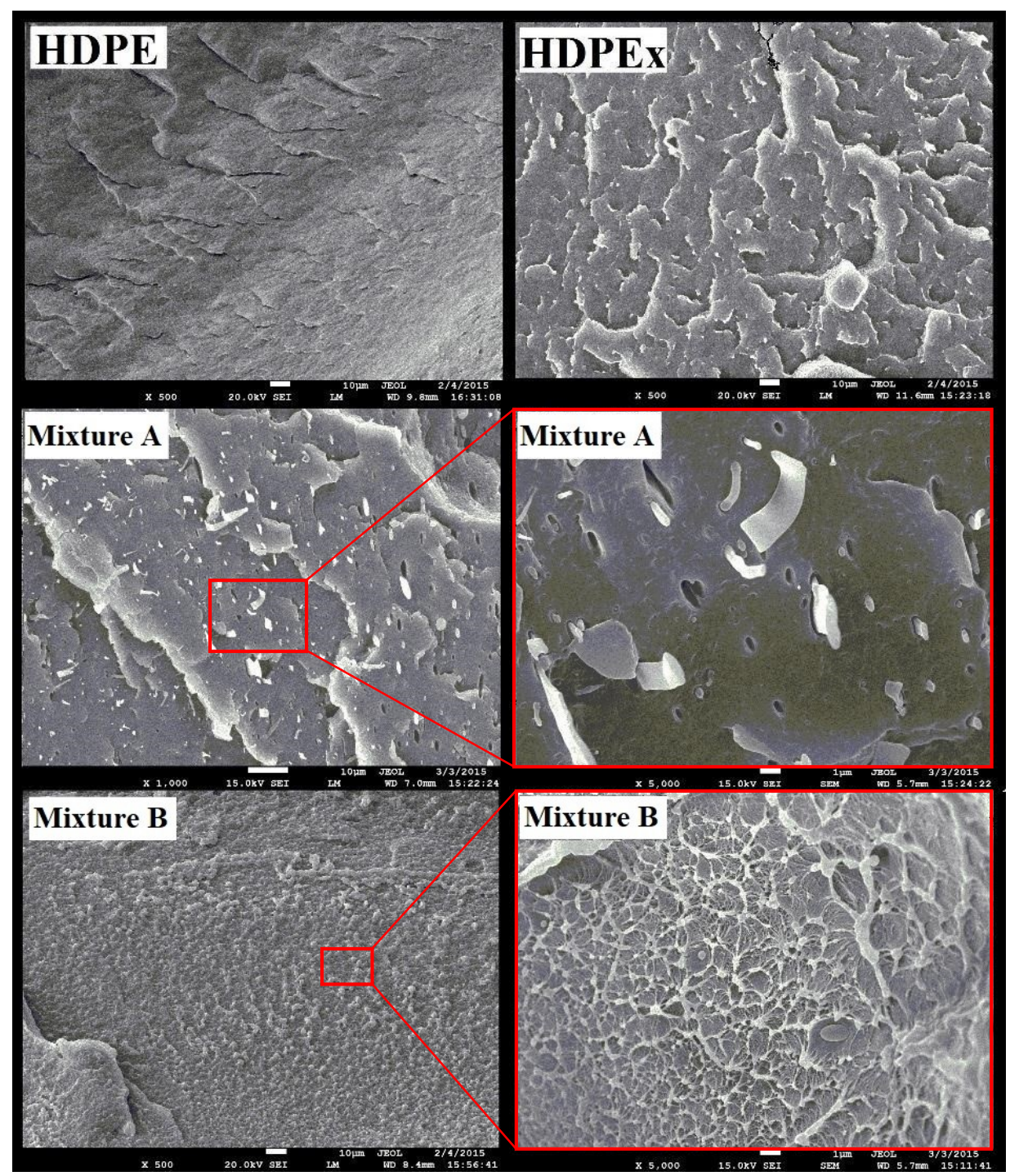

Figure 10. SEM-fracture surface structure.

\section{Conclusions}

The aim of this paper was to describe the possibility of using recycled high-density polyethylene (rHDPEx). For the purposes of this study, waste originating from the processing of underfloor heating pipes was used to examine the effect of the different sizes (of grit and powder) of the waste, and its concentration in the matrix on the mechanical properties and the ability to process the prepared mixtures.

It was found that the addition of rHDPEx to virgin HDPE did not deteriorate the mechanical properties of the composite; on the contrary, in some cases-improvements occurred. An HDPE-based composite with a filler of recycled radiation cross-linked rHDPEx may be processed by injection-moulding up to $60 \mathrm{wt} \%$. At this maximum dose, only a slight decrease in the flow-ability in the spiral, (about 35\%), occurred. On the one hand, higher concentrations caused problems with product-compactness; while, on the other hand, it was necessary to increase the injection pressure to avoid clogging the injection sprue or prematurely freezing of the injection gate. No delamination at the HDPE and rHDPEx phase interface was observed for all concentrations tested. 
The following results can be highlighted:

- The measured properties of the new composite change only slightly. The composite properties are superior to those of the virgin HDPE.

- It is possible to use the rHDPEx filler in the form of grit or powder.

- Both mixtures-HDPE with rHDPEx as filler, can be processed by injection-moulding up to a filler content of $60 \mathrm{wt} \%$.

- One can say that a new way of waste-processing from radiation cross-linked polymer (rHDPEx) has been found.

The proposed processing method is very simple and involves only a few steps-(crushing or grinding of rHDPEx waste), and requires relatively small investments and low energy costs for the preparation of the given filler (rHDPEx). The method of using radiation cross-linked rHDPEx can be extended by further steps like the preparation of the given granulate mixture. However, the studies and tests that were conducted show that it is possible to dispense the powder directly into the HDPE matrix, thereby achieving very good properties for the new composite that are fully comparable with the original HDPE and without any unnecessary increase in recycling costs. The proposed method opens the way to an economically interesting manner of processing otherwise difficult to apply polymer waste.

The expansion of polymer waste from irradiated products is expected in the future. The radiation cross-linking technique has become the common way of modifying thermoplastic properties; not only HDPE but also engineering plastics like PP, PA, PBT etc. are irradiated. In a few years time their end-of-life period will finish, so the question is how to recycle this waste?

Author Contributions: D.M. and J.N. designed and performed the experiments; P.S., P.D. and S.S. analysed the data; M.M. and A.M. conceived and designed the experiments and wrote the paper.

Funding: This work was supported by the European Regional Development Fund under the project CEBIA-Tech Instrumentation No. CZ.1.05/2.1.00/19.0376 and by the Ministry of Education, Youth and Sports of the Czech Republic within the National Sustainability Programme project No. LO1303 (MSMT-7778/2014).

Acknowledgments: Our great thanks belong to our colleague and co-worker, David Manas for his long lasting cooperation and supervision of numerous academic diploma works and theses. David was a promising - and highly regarded pedagogue and scientist; and a leading person in the research area presented in this article. He passed away unexpectedly in mid-September 2017, at the age of only 42 years of life. We were honoured to work with him. May his soul rest in peace. The authors of this article would especially like to thank the firm-BGS, Germany, and Michal Danek especially, for their kind assistance in the realisation of radial cross-linking.

Conflicts of Interest: The authors declare no conflict of interest.

\section{References}

1. Ignatyev, I.A.; Thielemans, W.; Vander Beke, B. Recycling of Polymers: A Review. ChemSusChem 2014, 7, 1579-1593. [CrossRef] [PubMed]

2. Hubo, S.; Leite, L.; Martins, C.; Ragaert, K. Evaluation of post-industrial and post-consumer polyolefin-based polymer waste streams for injection moulding. In Proceedings of the 6th Polymers \& Mould Innovations International Conference, University of Minho, Guimarães, Portugal, 10-12 September 2014; pp. 201-206.

3. Brandrup, J. Recycling and Recovery of Plastics; Hanser Publishers: Munich, German, 1996.

4. Ragaert, K.; Delva, L.; Geem, K.V. Mechanical and chemical recycling of solid plastic waste. Waste Manag. 2017, 69, 24-58. [CrossRef] [PubMed]

5. Oblak, P.; Gonzalez-Gutierrez, J.; Zupančič, B.; Aulova, A.; Emri, I. Processability and mechanical properties of extensively recycled high density polyethylene. Polym. Degrad. Stab. 2015, 114, 133-145. [CrossRef]

6. Al-Salem, S.; Lettieri, P.; Baeyens, J. Recycling and recovery routes of plastic solid waste (PSW): A review. Waste Manag. 2009, 29, 2625-2643. [CrossRef] [PubMed]

7. Hopewell, J.; Dvorak, R.; Kosior, E. Plastics recycling: challenges and opportunities. Philos. Trans. R. Soc. Lond. B Biol. Sci. 2009, 364, 2115-2126. [CrossRef] [PubMed]

8. Bajracharya, R.M.; Manalo, A.C.; Karunasena, W.; Lau, K.T. Characterisation of recycled mixed plastic solid wastes: Coupon and full-scale investigation. Waste Manag. 2016, 48, 72-80. [CrossRef] [PubMed] 
9. Díaz, S.; Ortega, Z.; McCourt, M.; Kearns, M.P.; Benítez, A.N. Recycling of polymeric fraction of cable waste by rotational moulding. Waste Manag. 2018, 76, 199-206. [CrossRef]

10. Stenvall, E.; Tostar, S.; Boldizar, A.; Foreman, M.R.; Möller, K. An analysis of the composition and metal contamination of plastics from waste electrical and electronic equipment (WEEE). Waste Manag. 2013, 33, 915-922. [CrossRef]

11. Censori, M.; Marca, F.L.; Carvalho, M.T. Separation of plastics: The importance of kinetics knowledge in the evaluation of froth flotation. Waste Manag. 2016, 54, 39-43. [CrossRef]

12. Arvanitoyannis, I.S.; Bosnea, L.A. Recycling of polymeric materials used for food packaging: current status and perspectives. Food Rev. Int. 2001, 17, 291-346. [CrossRef]

13. Rem, P.; Maio F.D.; Hu, B.; Houzeaux, G.; Baltes, L.; Tierean, M. Magnetic fluid equipment for sorting secondary polyolefins from waste. Environ. Eng. Manag. J. 2013, 12, 951-958.

14. Baričević, A.; Rukavina, M.J.; Pezer, M.; Štirmer, N. Influence of recycled tire polymer fibers on concrete properties. Cement Concrete Compos. 2018, 91, 29-41. [CrossRef]

15. Stenvall, E.; Boldizar, A. Mechanical and Thermal Characterization of Melt-Filtered, Blended and Reprocessed Post-Consumer WEEE Thermoplastics. Recycling 2016, 1, 89-100. [CrossRef]

16. Puig-Arnavat, M.; Bruno, J.C.; Coronas, A. Review and analysis of biomass gasification models. Renew. Sustain. Energy Rev. 2010, 14, 2841-2851. [CrossRef]

17. Angyal, A.; Miskolczi, N.; Bartha, L. Petrochemical feedstock by thermal cracking of plastic waste. J. Anal. Appl. Pyrolysis 2007, 79, 409-414. [CrossRef]

18. Kumar, A.; Jones, D.D.; Hanna, M.A. Thermochemical Biomass Gasification: A Review of the Current Status of the Technology. Energies 2009, 2, 556-581. [CrossRef]

19. Kögel, G. Synthesegas aus Kunststoffabfällen. K Magazin, 3 July 2018, pp. 40-41.

20. Lubos, P. Schluss mit der Recyclinglüge. K Magazin, 26 June 2018, pp. 10-14.

21. Emans, T. Immer größere Kapazitäten für PE. K Magazin, 28 June 2018, p. 20.

22. Packaging recycling in US rises by 10\%. Film and Sheet Extrusion, March 2018, p. 11.

23. Nikolić, M.A.; Gauthier, E.; Colwell, J.M.; Halley, P.; Bottle, S.E.; Laycock, B.; Truss, R. The challenges in lifetime prediction of oxodegradable polyolefin and biodegradable polymer films. Polym. Degrad. Stab. 2017, 145, 102-119. [CrossRef]

24. Laycock, B.; Nikolić, M.; Colwell, J.M.; Gauthier, E.; Halley, P.; Bottle, S.; George, G. Lifetime prediction of biodegradable polymers. Prog. Polym. Sci. 2017, 71, 144-189. [CrossRef]

25. Drobny, J.G. 9-Safety and Hygiene. In Ionizing Radiation and Polymers; Drobny, J.G., Ed.; Plastics Design Library, William Andrew Publishing: Norwich, NY, USA, 2013; pp. 237-243.

26. Rouif, S. Radiation cross-linked polymers: Recent developments and new applications. Nuclear Instrum. Methods Phys. Res. Sect. B Beam Interact. Mater. At. 2005, 236, 68-72. [CrossRef]

27. Gehring, J. With radiation crosslinking of engineering plastics into the next millennium. Radiat. Phys. Chem. 2000, 57, $361-365$. [CrossRef]

28. Navratil, J.; Manas, M.; Mizera, A.; Bednarik, M.; Stanek, M.; Danek, M. Recycling of irradiated high-density polyethylene. Radiat. Phys. Chem. 2015, 106, 68-72. [CrossRef]

29. Burillo, G.; Clough, R.L.; Czvikovszky, T.; Guven, O.; Moel, A.L.; Liu, W.; Singh, A.; Yang, J.; Zaharescu, T. Polymer recycling: potential application of radiation technology. Radiat. Phys. Chem. 2002, 64, 41-51. [CrossRef]

30. Adem, E.; Avalos-Borja, M.; Carrillo, D.; Vazquez, M.; Sanchez, E.; Carreon, M.; Burillo, G. Crosslinking of recycled polyethylene by gamma and electron beam irradiation. Radiat. Phys. Chem. 1998, 52, 171-176. [CrossRef]

31. Navratil, J.; Manas, M.; Stanek, M.; Manas, D.; Bednarik, M.; Mizera, A. Influence of Recycled Irradiated HDPE on Mechanical Behavior of LDPE/Hdpex Blends. Adv. Mater. Res. 2014, 1025, 265-269. [CrossRef]

32. Tokuda, S.; Horikawa, S.; Negishi, K.; Uesugi, K.; Hirukawa, H. Thermoplasticizing technology for the recycling of crosslinked polyethylene. Furukawa Rev. 2003, 23, 88-93.

33. Sam Janajreh, I.; Alshrah, M. Remolding of Cross-Linked Polyethylene Cable Waste: Thermal and Mechanical Property Assessment. Int. J. Therm. Environ. Eng. 2013, 5, 191-198.

34. Qudaih, R.; Janajreh, I.; Vukusic, S. Recycling of Cross-linked Polyethylene Cable Waste via Particulate Infusion. In Advances in Sustainable Manufacturing; Springer: Berlin/Heidelberg, Germany, 2011; pp. 233-239. 
35. Manas, D.; Manas, M.; Mizera, A.; Navratil, J.; Ovsik, M.; Tomanova, K.; Sehnalek, S. Use of Irradiated Polymers after Their Lifetime Period. Polymers 2018, 10, 641. [CrossRef]

36. Practice for Calibration of Routine Dosimetry Systems for Radiation Processing; International Organization for Standardization: Geneva, Switzerland, 2013.

37. Standard Test Method for Determining Gel Content in Crosslinked Ethylene Plastics Using Pressurized Liquid Extraction (Withdrawn 2015); ASTM International: West Conshohocken, PA, USA, 2009.

38. Plastics-Determination of Tensile Properties; International Organization for Standardization: Geneva, Switzerland, 2012.

39. Stanek, M.; Manas, D.; Manas, M. Stavebnicova Testovaci Vstrikovaci Forma; Uzitny vzor 23338; Urad Prumysloveho Vlastnictvi: Prague, Czech Republic, 2012.

40. Plastics and Ebonite-Determination of Indentation Hardness by Means of a Durometer (Shore Hardness); International Organization for Standardization: Geneva, Switzerland, 2003.

41. Plastics - Thermoplastic Materials_Determination of Vicat Softening Temperature; International Organization for Standardization: Geneva, Switzerland, 2013.

(c) 2018 by the authors. Licensee MDPI, Basel, Switzerland. This article is an open access article distributed under the terms and conditions of the Creative Commons Attribution (CC BY) license (http://creativecommons.org/licenses/by/4.0/). 